\title{
On the relationship between multiple intelligences and self-actualization among Iranian EFL learners
}

\author{
ShirzadMoghaddam, Elnaz \\ Tabaran Institute of Higher Education, Mashhad, Iran (Elnazshirzad@yahoo.com) \\ Ghapanchi, Zargham \\ Ferdowsi University of Mashhad, Mashhad, Iran (ghabanchi@um.ac.ir)
}

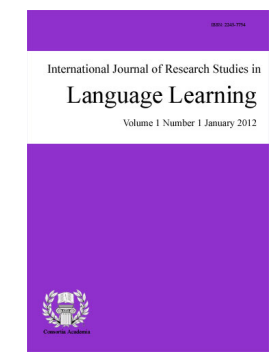

ISSN: 2243-7754 Online ISSN: 2243-7762

OPEN ACCESS

\section{Abstract}

The present study aimed at taking steps to draw language instructors to new educational approaches in foreign language learning context in which the learners' potentials concerning target language skills are realized at their maximum rate. To that end, the researchers opted to investigate the correlation between multiple intelligences theory and self-actualization to find out if any of the intelligence types as well as total multiple intelligence scores are significantly related to learners' self-actualization. To collect the data, 278 junior students majoring in English language teaching and English literature at B.A. level were randomly selected from several universities of Razavi Khorasan province, Iran to answer the questionnaires. After the two completed questionnaires of multiple intelligences and short index of self-actualization were collected, the data were analyzed by Statistical Package for the Social Science (SPSS) software. The results revealed that among nine multiple intelligence types; naturalist, linguistic, logical-mathematical, intrapersonal, and existential intelligences are significantly related to self-actualization. Furthermore, it was demonstrated that there is a statistically significant relationship between total multiple intelligence scores and self-actualization. Finally, multiple regression analysis was run to find out the intelligence type that makes the most contribution to the prediction of self-actualization. The results showed that intrapersonal intelligence is the best predictor of self-actualization which uniquely explained 6.8 percent of the variance in self-actualization score.

Keywords: intelligence types; potentials realization; short index of self-actualization; EFL learners; language skills 


\section{On the relationship between multiple intelligences and self-actualization among Iranian EFL learners}

\section{Introduction}

Maslow (1943) proposed the theory of human motivation as to explain what sorts of need motivate humans to behave in particular ways. In his suggested model of humans' hierarchy of needs, self-actualization is indicated as the highest need level activated on the condition that its lower needs level, namely; physiological, safety, love, and self-esteem needs have been respectively well gratified. Self-actualization refers to realizing one's full potentials and making the most of what one is capable of doing. It is worth mentioning that in self-actualization definition, it has been talked about the realization of 'potentials' rather than talents or abilities. In this respect, Rosenbloom (2012) made distinctions between talents and potentials so that talent is the natural ability a human owns in present while potential refers to the possibility of doing a great job in future for which a one's talent could be effective, in other words, a persons' talent is the prerequisite for realizing his inner potentials regarding the coaching or training he acquires.

The purpose of the present study for taking the highest need level of Maslow's hierarchical needs theory, which is self-actualization, into consideration in foreign language learning context is to recommend language instructors to take individual differences among learners into account so as to make learning effective for all the students. Moreover, individualistic differences here mainly point to affective factors such as; motivation, attitudes, and anxiety (Horwitz, 2008). In previous studies concerning self-actualization application in language learning environment, it has been assumed to consider self-actualization as a principle on which humanistic education is based, for instance, Mehrgan (2012) placed self-actualization as one of his five stated tenets of humanistic education. In addition, Seidi, Dastnaee, Abadati, and Dehnavi (2013) suggested the implications of each need level of Maslow's hierarchical needs in language teaching in a humanistic framework so that Maslow's theory is viewed as an approach towards humanizing foreign language learning. Furthermore, with regard to humanistic education in which self-actualization is included, Stevick (as cited in Mehrgan, 2012) proposed five emphases within humanism, namely; feelings, responsibility, intellect, social relations, and self-actualization. Therefore, it is helpful to continue the current paper's lines with elaborations regarding self-actualization characteristics and their outcomes in terms of foreign language learning context.

Maslow (1970) believed that only low percentage of people might reach self-actualization and it is almost impossible for many people to achieve it completely. He stated self-actualizing people possess particular characteristics following: perception of reality and the sense of tolerance for facing uncertainties, acceptance of others with their present personality, spontaneity in actions and thoughts, focusing on problems rather than the benefit for themselves, having objective look at life events instead of subjectively considering matters, having high sense of creativity, resisting enculturation in spite of believing in democracy, establishing deep relationships at least with few people, and strongly believing in ethical and moral standards (McLeod, 2016). Although self-actualizers are not necessarily known with the collection of all the mentioned characteristics at once, they share many of those characteristics with the purpose of actualizing their inner potentials in terms of whatever they can achieve based on their potentials realization. Maslow (1970) did not equate self-actualization with perfectionism since he believed there is no perfect human being in the world, therefore self-actualization is taken as a matter of degree rather than a fixed factor.

Language learning puts learners in anxious situations when they are experiencing the moments dealing with the target language (Rubio, 2007), thus many researchers in the past decades have undertaken studies to investigate the employment of strategy types by which learners might overcome the negative emotions existing in SL/FL contexts. Emotional intelligence has been known as one the factors influencing language learning, for instance, according to Weiler (2015), people with higher EQ are better able to deal with negative emotions such 
as: worry, embarrassment, and shame. Emotional intelligence causes people to manage their emotions in tough conditions and be aware of other people's emotions and needs as well (Pausanos, 2014). In the research conducted by Pausanos (2014), it was indicated that emotional intelligence is considered as a predictor of self-actualization which emphasizes the role of emotional intelligence treatment in FL/SL contexts in order to create sufficient intrinsic motivations in learners to cooperatively work with their friends via the relationships they make with each other, consequently learners with high EQ not only will be more successful at communicative tasks of language learning but also their self-actualization will be developed as a result. In a similar vein, Mohamadi, Alishahi, and Soleimani (2014) conducted a research that proved there is a negative relationship between students' test anxiety and their self-actualization which highlights the role of self-actualization consideration in eliminating students' feeling of anxiety while taking a test.

Two terms of interaction and social relationships are dynamically playing a role in foreign language learning. Thus the learner should act as a socially responsible person who not only has the capacity to work independently but also to work cooperatively with others (Dam et al., 1990; as cited in Najeeb, 2013). Such process of shift from traditional method of teaching in which teacher was the only responsible role in learning to the cooperative learning method makes learners more involved through the learning process. Consequently, they might most of the time feel enthusiastic and eager about learning due to the accountability of learning and teaching put on them, on the other hand, self-actualization enhances learners' interpersonal relationships and keep them fresh during the learning moments (Khan \& Javed, 2012). Hence with regard to positive points of cooperative learning, self-actualization development will enable learners to efficiently learn the target language by the effective relationships they make with their classmates.

With regard to Maslow's theory of human motivation, Self-actualization brings about a sense of creativity in learners (McLeod, 2016). Creativity has been studied by researchers in the field of language learning such as Ševečková (2016) that recommended language instructors to incorporate creativity in their pedagogy via the application of play, collaboration, interaction, and fantasy to classrooms. Ševečková (2016) mentioned if language learners learn the language in the environment in which they freely express their ideas without any fear of the outcome, creativity can arise. To that end, it was recommended to be in the exposure of language so that mutual feedback and teamwork activities exist in that context. In the study conducted by ShirzadMoghaddam (2016), it was mentioned that the habit of self-reflection leads to self-actualization in language learners, in other words, by the application of self-reflection learners will be aware of their weak points and can improve their language skills by evaluating their performances. In conclusion, self-actualization is the step where language learners are able to autonomously learn the language by the employment of creativity and as a result could view the learning process as a lifelong passion (Ševečková, 2016).

According to Maslow (as cited in Bordages, 1989), it is hypothesized that self-actualized individuals are likely to operate autonomously of any external expectations; with this respect, Bordages (1989) undertook a research to find the relationship between personal autonomy and the degree of self-actualization. The research analyses indicated that there is a positive relationship between personal autonomy and self-actualization so that moderate and high self-actualizing participants showed higher amount of personal autonomy. Qamar' (2016) study results revealed that learners' autonomy in EFL classrooms has positive impacts on their oral skills, furthermore in another study conducted by Salehi, Ebrahimi, Sattar, and Shojaee (2015), it was concluded that there is a positive correlation between degrees of learner autonomy, use of strategies for coping with speaking problems, and their success in speaking classrooms. Zarei and Gahremani (2010) undertook the research to find out if there is a relationship between learners' autonomy and their reading comprehension based on 68 participants' filling out the questionnaires. Their results indicated that the autonomous learners gained better scores in their reading comprehension tests. Moreover, Garcia and Pintrich (1991) as a result of their research findings on 365 college students of four institutions concluded that autonomy has positive effects on all constructs of motivation and consequently fosters students' intrinsic motivation.

In 1983, Howard Gardner, an American psychologist, proposed a different perspective of human intellectual 
competence called 'Multiple Intelligence Theory'. His intellectual view consisted of seven intelligences: logical-mathematical, linguistic, musical, spatial, bodily-kinesthetic, interpersonal, and intrapersonal. In 1995, he added the eighth intelligence as naturalist and four years later the possibility of the ninth intelligence as existential (Gardner, 2004). He believed MI theory should be viewed as a tool in curriculum development so as to help students reach the educational goal on the basis of the nine different intelligences combined in syllabus designing (Gardner, 2004). MI theory is the replacement of traditional IQ tests mostly probing linguistic and mathematical intelligences. Actually it was by the theory of Gardner's multiple intelligences that the individual differences beyond the traditional notions of linguistic and mathematical competences were taken into consideration with the aim of indicating that a human's skills can be developed if the intelligences needed for that particular profession be adequately activated. In spite of the fact that people are born with various profiles of intelligences, Armstrong (2009) mentioned in his book that the key point in MI theory is that all human beings have the capacity to develop all intelligence types to a mastery level with regard to their life history or cultural backgrounds, in other words, the development of all intelligences depends on chances people find in their life experiences.

The application of multiple intelligences is viable through classroom tasks, such as involving linguistic and musical intelligences while writing song lyrics or bodily-kinesthetic and interpersonal intelligences when miming the title of a film (Arnold \& Fonscca, 2004). In the realm of visual-spatial frame, Sadoski, Goetz, and Avila (1995) mentioned that in L1 reading comprehension, the ability of evoking images while reading the text is a better predictor of successful comprehension than the familiarity with the context of the text. Moreover, the application of visual aids such as; chart, diagrams, pictures, slides, and posters assist learners in information retrieval. The use of logical-mathematical intelligence in language classroom causes learners to be deeply involved in texts reading as a kind of problem-solving task in order to acquire knowledge in terms of texts vocabulary or structure (Arnold \& Fonscca, 2004). Bodily-kinesthetic intelligence gets learners to keep their energy levels at high rate during the session so that they are constantly ready to learn the lessons instruction with the same attention they had at initial session moments. Furthermore, intrapersonal intelligence has also been effectively applied to language learning context so that it emphasizes the efforts the learner makes in gaining knowledge of his/her own strengths and weaknesses. Khodadady and Khodabakhshzade (2012) conducted a research into the effect of portfolio and self-assessment on language learners' writing ability and autonomy that indicated learners under the influence of portfolio and self-assessment treatment gain higher self-regulation as a result. Naturalist and existential intelligences were the two last terms proposed by Gardner (1995, 1999) that have the possibility of their own application to foreign or second language learning context, for example the more learners are competent in describing their surrounding natural world, the more capability they will end up with in speaking as well as writing skill (Derakhshan \& Faribi, 2015). Existential intelligence the same as naturalist frame enables learners to understand in a larger context that could result in a better comprehension of different text types while reading as well as to prepare them for writing skills.

In spite of the above background and the studies so far have been done in language learning field, no studies have already been conducted to investigate the relationship between MI theory and self-actualization, to make it clear not any analyses have been made to consider multiple intelligences as predictors of self-actualization particularly in foreign language learning context, therefore the researchers aimed to apply MI theory in correlation with self-actualization to find out if teachers can rely on the use of MI as an approach towards supporting students' self-actualization achievement

\subsection{Significance of the study}

Learning a new language should be viewed as a dynamic phenomenon which is in contrast with training a full-fledged learner within the confines of school classrooms, in other words, being a competent target-language speaker cannot be accomplished solely on the basis of teachers' instructions. To that end, learners themselves should take the responsibility of their own learning to successfully encounter with the difficulties of learning process that might occur the moments outside the classroom time period. According to the Gardner's theory of 
MI, there are nine various ways by which the brain processes information, thinks, and solves problems (Sahatsatatsana \& Siriyothin, 2010). The application of MI theory to educational system causes learners to enjoy learning for the variety and creativity it brings into classroom atmosphere (Armstrong, 2009). Therefore, the results of the current study in case of the existence of significant relationship between multiple intelligences as a whole or each one of the intelligence types and self-actualization draw language teachers' attention to the application of Gardner's MI theory to their classrooms context so as not only to boost up students' self-actualization but also to make learners more pleased with their own learning since their strengths with the help of multiple intelligences application become pleasantly confirmed and encouraged.

Self-actualization regarding its features is assumed as a facilitative characteristic in language proficiency. With regard to the importance of special characteristics self-actualization brings about in people, self-actualizers as intrinsically motivated and energized personalities could form the backbone of society (Rawat, 2015). Learning languages independently beyond the classroom instructions, overcoming the feelings of fear and uncertainty in language skills performance, constructing effective relationships with classmates in cooperative tasks, having self-awareness and high control over one's own actions, and being hopeful of every drive for language skills achievements are all the results of self-actualization accomplishment. Self-actualized students have high sense of creativity as well. Ottó' (1998) study results revealed that there is a significant relationship between language learners' creativity and their overall language proficiency so that it was indicated in his research that creativity causes language learners to have higher sense of imagination leading them to be more active in the tasks of discussions and role-plays in communicative language teaching classrooms. Thus teachers should change the method of teaching as to support self-actualization growth among students not only for the purpose of more effective learning but to remove much more amount of teaching burden out of teachers' responsibility with the help of provoking students to be more engaged through classroom activities.

With regard to the emphasis this study has on self-actualization growth due to its benefits in English language proficiency achievement, MI theory was conducted to find out its relationship with self-actualization. The multiple intelligences with relation to self-actualization were analyzed not only as a whole but also each of them separately to find out if any of those intelligences could be taken as the best predictor of self-actualization. To that end, following research questions were addressed:

$>$ Q1: Is there any significant relationship between Iranian EFL learners' multiple intelligences as a whole and their self-actualization?

$>$ Q2: Is there any significant relationship between each one of the Iranian EFL learners' linguistic, interpersonal, intrapersonal, naturalistic, spatial-visual, musical, bodily-kinesthetic, logical-mathematical, and existential intelligences and their self-actualization?

Q3: Which one of the multiple intelligences can best predict self-actualization?

\section{Method}

\subsection{Participants}

Participants of this research were randomly selected from academic setting of universities located in Khorasan Razavi province, Iran based on the condition of researchers' accessibility. The population size which incorporated junior B.A. students majoring in English language teaching and English literature in Khorasan Razavi province was estimated to be 1000 students regarding the researchers' findings through accessible statistical data. The sample size out of this population was calculated on the basis of Krejcie and Morgan (1970) table with the confidence of $95 \%$ and 0.05 degree of accuracy. According to the sample size table, 278 students were chosen for this study. The participants of this study were junior B.A. students (63 male, 215 female) majoring in English language teaching and English literature whose ages ranged from 18 to 35. It is worth 
ShirzadMoghaddam, E., \& Ghapanchi, Z.

mentioning that in this study, the gender of participants whether male or female was not taken as a determining factor in results analysis.

\subsection{Instruments}

To determine participants' multiple intelligences, McKenzie's (1999) Multiple Intelligence Inventory was used. The mentioned tool includes nine sections with ten statements in each so as to assess each of the nine participants' intelligences: linguistic, musical, logical-mathematical, existential, interpersonal, bodily-kinesthetic, naturalist, intrapersonal, and visual-spatial intelligences. Participants were required to put 1 if the statement describes them, otherwise leave it blank as a meaning of value 0 . The reliability of the questionnaire based on Cronbach Alpha is $\alpha=.91$ (Khonbi \& Mohammadi, 2015).

Short index of self-actualization innovated by Jones and Crandall (1986) as the second tool in data collection procedure was administered to participants to assess their self-actualization. The short index of self-actualization, which consists of 15 items, was derived from Personal Orientation Inventory. The questionnaire is based on a four-point Likert-type scale ranging from disagree to agree. The index reliability as a result of Cronbach Alpha calculated by Jones and Crandall (1986) is $\alpha=.65$.

\subsection{Procedure}

The items of the two questionnaires were precisely typed by researchers to ensure that not any misspellings existed or the formats were comprehensible to the participants. Permissions from instructors were taken in advance to make sure that the administration start time in terms of classroom disciplines was convenient to get students to complete the questionnaires. It took about 35 minutes for participants to finish answering the questionnaires. Apart from the questionnaire items, two parts concerning age and gender were asked to be filled, however they were not taken as determining factors in the current research results. To achieve reliable results, students were asked not to write their names to make them sure that their identification was not a matter for researchers.

\subsection{Data analysis}

To analyze the collected data, Statistical Package for the Social Science (SPSS) software, version 16 was used. Initially, the normality of data was determined by descriptive statistics. Then the parametric test of Pearson Product-Moment correlation was applied to figure out the relationships between total multiple intelligence scores and self-actualization which is the first research question as well as each one of intelligence types and self-actualization that is the second research question of this study. In response to the third research question, multiple regression analysis was run to find out the predictability of groups of intelligences and accordingly to determine which intelligence can best predict self-actualization.

\section{Results}

In this section, seven tables with their descriptions concerning the study results have been displayed. First the normality of data was checked to ensure the viability of parametric test running. Then, in next subsections research questions are answered in order on the basis of results shown in tables.

\subsection{Data normality checking}

In Table 1, descriptive statistics including variables of intelligence types, self-actualization, total scores for multiple intelligences, skewedness ratio, and kurtosis ratio are displayed. To check the normality of distributions, calculated values of skewedness ratio and kurtosis ratio are checked and since they fall within -1.96 and +1.96 (Tabachnick \& Fidell, 2007), we can conclude the data for each one of the intelligence types, multiple intelligences as a whole, and self-actualization are normally distributed. Therefore the researcher was allowed to 
On the relationship between multiple intelligences and self-actualization among Iranian EFL learners

run parametric test of Pearson product-moment correlation for answering the research questions.

\section{Table 1}

Descriptive Statistics of Intelligence Types and Self-actualization

\begin{tabular}{lccccccc}
\hline \multicolumn{1}{c}{\begin{tabular}{l} 
Intelligences and \\
\multicolumn{1}{c}{ Self-actualization }
\end{tabular}} & $N$ & Mean & SD & Skewness & SE & Kurtosis & SE \\
\hline Naturalist & 278 & 7.97 & 1.07 & -.458 & .146 & .172 & .291 \\
Musical & 278 & 4.33 & 1.08 & .449 & .146 & -1.087 & .291 \\
Mathematical & 278 & 7.90 & 1.06 & -.402 & .146 & -.186 & .291 \\
Existential & 278 & 8.11 & 1.10 & -.497 & .146 & .082 & .291 \\
Interpersonal & 278 & 4.49 & 1.14 & .486 & .146 & -.804 & .291 \\
Bodily & 278 & 4.07 & 1.16 & .333 & .146 & -.303 & .291 \\
Linguistic & 278 & 8.05 & 1.06 & -.491 & .146 & .018 & .291 \\
Intrapersonal & 278 & 8.44 & 1.00 & -.387 & .146 & -.089 & .291 \\
Visual & 278 & 4.20 & 1.08 & .598 & .146 & -.770 & .291 \\
Multiple intelligences & 278 & 57.43 & 6.36 & -.290 & .146 & .251 & .291 \\
Self-actualization & 278 & 51.04 & 5.46 & -.639 & .146 & .779 & .291 \\
Valid N (listwise) & 278 & & & & & & \\
\hline
\end{tabular}

\subsection{Answering the first research question}

The first research question of the current study sought to figure out any significant relationship between multiple intelligences as a whole and self-actualization. To this end, the data were analyzed using the Pearson correlation coefficient. Table 2 shows the results of this analysis.

\section{Table 2}

Pearson's Correlation between Multiple intelligences as a whole and Self-actualization

\begin{tabular}{llcc}
\hline \multicolumn{1}{c}{ Variable } & Correlation & $\begin{array}{c}\text { Multiple } \\
\text { intelligences }\end{array}$ & Self-actualization \\
\hline & Pearson & 1 & $.456^{* *}$ \\
Multiple intelligences & Sig. & & .000 \\
& $\mathrm{~N}$ & 278 & 278 \\
\hline Note. ${ }^{* *}$. Correlation is significant at the 0.01 level (2-tailed).
\end{tabular}

According to the results of the analysis reported in Table 2, there is a significant relationship between multiple intelligences as a whole and self-actualization, $\rho=.45, \mathrm{n}=278, p<.01$. Therefore, it is concluded that there is a significant relationship between multiple intelligences as whole and self-actualization among Iranian EFL learners.

\subsection{Answering the second research question}

The second research question of the study was to find out the relationship between each one of the Iranian EFL learners' linguistic, interpersonal, intrapersonal, naturalistic, spatial-visual, musical, bodily-kinesthetic, logical-mathematical, and existential intelligences and their self-actualization. To do that, the data were analyzed using the Pearson coefficient of correlation which is a parametric test. The results displayed in Table 3 and 4 show the answers to the mentioned research question.

As tables 3 and 4 demonstrate, there is a significant and positive relationship between naturalist intelligence and self-actualization, $\rho=.52, \mathrm{n}=278, p<.01$, between logical-mathematical intelligence and self-actualization, $\rho=.51, \mathrm{n}=278, p<.01$, between existential intelligence and self-actualization, $\rho=.54, \mathrm{n}=278, p<.01$, 
ShirzadMoghaddam, E., \& Ghapanchi, Z.

between linguistic intelligence and self-actualization, $\rho=.53, \mathrm{n}=278, p<.01$, and as well as intrapersonal intelligence and self-actualization, $\rho=.61, \mathrm{n}=278, p<.01$.

\section{Table 3}

Correlation between Naturalist, Musical, Mathematical, Existential, and Interpersonal and Self-actualization

\begin{tabular}{ccccccccc} 
Variable & Correlation & Self-actualization & Naturalist & Musical & Mathematical & Existential & Interpersonal \\
& Pearson & 1 & $.520^{* *}$ & .008 & $.514^{* *}$ & $.547^{* *}$ & .052 \\
Self-actualization & Sig. & & .000 & .898 & .000 & .000 & .385 \\
& $\mathrm{~N}$ & 278 & 278 & 278 & 278 & 278 & 278 \\
\hline
\end{tabular}

Note. ${ }^{* *}$. Correlation is significant at the 0.01 level (2-tailed).

\section{Table 4}

Correlation between Bodily, Linguistic, Intrapersonal, and Visual Intelligences and Self-actualization

\begin{tabular}{clccccc} 
Variable & Correlation & Self-actualization & Bodily & Linguistic & Intrapersonal & Visual \\
\hline & Pearson & 1 & -.022 & $.539^{* * *}$ & $.613^{* *}$ & .022 \\
Self-actualization & Sig. & & .721 & .000 & .000 & .715 \\
& $\mathrm{~N}$ & 278 & 278 & 278 & 278 & 278 \\
\hline
\end{tabular}

Note. $* *$. Correlation is significant at the 0.01 level (2-tailed).

Based on the above mentioned findings, all of the intelligence types, except musical, interpersonal, bodily-kinesthetic, and visual-spatial intelligences were significantly related to self-actualization. In other words, out of nine intelligences, five of them were significantly correlated with self-actualization.

\subsection{Answering the third research question}

As it was earlier reported, the relationships between self-actualization and five out of nine multiple intelligence types were statistically significant. These five intelligence types were: naturalist, logical-mathematical, existential, linguistic, and intrapersonal intelligences. As a result, the researcher opted to answer to the third research question which is to find out the strongest predictor of self-actualization. To do that, a standard multiple regression analysis was run. Table 5 shows the variables of the regression model. Naturalist, logical-mathematical, existential, linguistic, and intrapersonal intelligences were the predictor variables and self-actualization was the predicted variable.

\section{Table 5}

Predictor variables

\begin{tabular}{cc}
\hline Variables & Method \\
\hline Intrapersonal & \\
Mathematical & \\
Existential & Enter \\
Naturalist & \\
Linguistic & \\
\hline
\end{tabular}

Table 6 demonstrates that there are significant linear relations between given variables and self-actualization. These variables are: naturalist, logical-mathematical, existential, linguistic, and intrapersonal intelligences. While, Table 7 displays the Standardized Beta Coefficients which conveys the degree to which each predictor variable contributes to the prediction of the predicted variable. The Sig. values show that among the five predictor variables, only intrapersonal intelligence can make a statistically significant contribution to the prediction of self-actualization. Finally, the inspection of Part correlation shows that intrapersonal intelligence uniquely explains 6.8 percent of the variance in self-actualization $(.262 \times .262=.068)$. 
On the relationship between multiple intelligences and self-actualization among Iranian EFL learners

Table 6

Regression analysis for existence of linear relation

\begin{tabular}{llccccc}
\hline Model & & Sum of Squares & df & Mean Square & $F$ & Sig. \\
\hline 1 & Regression & 3238.751 & 5 & 647.750 & 35.021 & .000 \\
& Residual & 5030.890 & 272 & 18.496 & & \\
& Total & 8269.640 & 277 & & & \\
\hline
\end{tabular}

Table 7

Regression Output

\begin{tabular}{lcccccc}
\hline Intelligences & $\mathrm{B}$ & SE & Beta & $t$ & Sig. & Correlations Part \\
\hline (Constant) & 21.270 & 2.276 & & 9.346 & .000 & .925 \\
Naturalist & .065 & .694 & .013 & .094 & .004 \\
Mathematical & .660 & .604 & .128 & 1.092 & .276 & .052 \\
Existential & .231 & .496 & .046 & .466 & .642 & .022 \\
Linguistic & .106 & .798 & .021 & .133 & .894 & .006 \\
Intrapersonal & 2.524 & .456 & .462 & 5.533 & .000 & .262 \\
\hline
\end{tabular}

\section{Discussion}

This study attempted to discover the ways by which EFL learners' potentials are maximized in terms of target language skills achievement. To that end, multiple intelligences theory was correlated with self-actualization to find out the relationship between total multiple intelligences as well as each of the intelligence types with self-actualization. Regarding the application of multiple intelligences to educational system since the past decades, the identification of those particular intelligences leading to students' self-actualization facilitate the process of target language learning for learners themselves so that they are sooner able to communicate independently. Apart from the role of self-actualization in language learning facilitation, self-actualized learners will end up with sorts of characteristics such as; autonomy, creativity, free of fear or anxiety, spontaneity in actions, and problem-centered rather than self-centered (McLeod, 2016) that all have resulted in target language achievement success based on studies that undertook the investigation into the correlation of each of them with English learning success.

According to the results of this study, linguistic, logical-mathematical, naturalist, intrapersonal, and existential intelligences were significantly correlated with self-actualization. Hence language instructors should integrate the mentioned intelligences into their lessons instruction as to promote learners' sense of realizing their potentials to competently perform target language skills. The application of any of those five intelligences in classrooms not only orients learners towards the realization of their inner potentials but also causes them to enjoy learning due to the variety of tasks and activities involved in terms of several intelligences combination. However, the use of what kinds of activities might activate these five intelligences depends on teacher' perception with regard to the level of EFL learners and their fields of interests as well as the environmental effective factors.

The concept of self-actualization in this study was mostly viewed concerning its features in a self-actualized learner as well as its general definition referring to maximizing one's potentials which emerges in different forms among people. Thus self-actualization in the present research is taken as an influential factor in foreign language achievement success by which and EFL learner ties his most to demonstrate what he is truly capable of doing. It is taken for granted that some learners fail in mastering target language skills although they have the talent and interest needed for learning languages. Therefore, it came to researcher's mind to undertake an investigation to study multiple intelligences in relation to self-actualization to see if any of the nine intelligence types is significantly correlated to self-actualization. In addition, the application of multiple intelligences to curriculum development brings about characteristics in learners which are the same as self-actualization ones, for instance, Arnold and Fonscca (2004) concluded as a result of their study that the activation of logical-mathematical 
intelligence in learners assists them in taking a problem-solving approach while reading texts which leads them to the higher knowledge of vocabulary and texts structures gaining. In a further study conducted by Khodadady and Khodabakhshzade (2012), it was revealed that self-assessment and portfolio arrangements, which are the tasks related to intrapersonal intelligence enhancement, improve learners' writing ability and their self-regulation as well.

It is worth mentioning that in this study, intrapersonal intelligence turned out to be the best predictor of self-actualization compared to the other four intelligences which were linguistic, logical-mathematical, naturalist, and existential intelligences. The significance of intrapersonal intelligence, which refers to the knowledge of oneself concerning his strengths and weaknesses, recommends language instructors to incorporate activities in terms of intrapersonal intelligence to make students deeply seek through themselves to discover the potentials hidden inside them and take steps to realize those potentials so as to master whatever they are good at. In spite of the fact that self-actualization orients people in keeping close relationships with at least few people, in this study it did not turn out to be significantly correlated with self-actualization. It seems that self-actualized learners prefer to spend time searching through themselves rather than believing in the necessity for keeping close relationships with people. However, in language learning especially communicative language learning method students are highly required to perform cooperative tasks via the relationships they form with their classmates with the aim of being prepared to communicate independently in target language which is the goal of language learning. With this respect, it is possible to state that interpersonal intelligence considers friendships as highly important need whereas in communicative language learning, learners should not have necessarily close relationships with their other classmates and spend much time in struggling to make themselves compatible with other students in classroom, instead they put most of their efforts in searching through their talents and realize their hidden potentials as a result.

Although the results of this study did not end up with significant relationships between other four intelligence types which are: visual-spatial, interpersonal, bodily-kinesthetic, and musical intelligences with self-actualization, it is not reasonable to conclude that the mentioned intelligences do not have any roles in characteristics leading to self-actualization achievement. Furthermore, it is possible to say that different results might appear if the relationship between multiple intelligences and self-actualization be considered in terms of specific language skills, namely, listening, speaking, writing, or speaking.

\section{Conclusion}

This study was conducted to investigate the relationship between two variables of multiple intelligences and self-actualization among Iranian EFL learners. In response to the first research question which was to find the relationship between multiple intelligences as a whole and self-actualization, the results of Pearson correlation analysis revealed that there is a statistically significant relationship between total multiple intelligences and self-actualization. Therefore, total multiple intelligences that consist of linguistic, interpersonal, intrapersonal, visual-spatial, bodily-kinesthetic, existential, musical, naturalist, and logical-mathematical intelligences are significantly correlated with self-actualization.

The second question of the present study was designed to answer whether there is a statistically significant relationship between each of the intelligence types and self-actualization. The results demonstrated that among nine intelligence types, five of them, namely, linguistic, intrapersonal, logical-mathematical, naturalist, and existential intelligences are significantly related to self-actualization. Finally, the third research question sought to find the best predictor of self-actualization among those five intelligences that were significantly correlated with self-actualization. In this respect, the results of multiple regression analysis showed that intrapersonal intelligence is the best predictor of self-actualization.

To sum up, this study was undertaken in academic setting of universities whose participants were students majoring in English teaching and literature. Moreover, regarding the sample size, one province of Iran country 
On the relationship between multiple intelligences and self-actualization among Iranian EFL learners

was included for data collecting. Therefore, further studies are recommended in terms of wider sample issues as well as incorporating translation major students and those learning English in private institutes which are different from university contexts. In conclusion, due to the fact that self-actualization moves learners towards autonomy, more studies are required to incorporate particular language skills in the realm of multiple intelligences and self-actualization.

\subsection{Pedagogical implications}

This study concentrated on explaining self-actualization contributions to English language achievement success. Hence multiple intelligences theory taken as a variable turned out to be significantly correlated with self-actualization improvement. The results of this study suggest changes in both teachers' and students' roles in teaching and learning so that EFL learners become more motivated to take responsibility for their own language learning and be able to view this learning process as a challenging and enjoyable part of their life. Self-actualization overcomes many of the affective issues that cause learners' failure in language learning such as; anxiety, fear of communication, lack of motivation, and low learners' tendency to cooperate in classroom tasks due to environmental factors. Thus teachers regarding the results of this study should integrate their syllabus designing with tasks activating learners' linguistic, intrapersonal, naturalist, existential, and logical-mathematical intelligences so as to train more self-actualized learners.

Curriculum developers and syllabus designers should incorporate lessons planning with self-reflection and self-assessment activities so that students' intrapersonal intelligence is activated and as a result this leads to the growth of students' self-actualization whose inner potentials are constantly searched through to be realized in form of foreign language achievements. Students' attention should be drawn into discovering their talents and weak points and accordingly they take essential steps to progress on the basis of their talents and overcome their weaknesses by strategies gained by instructions. It is possible to conclude that if students get informed of their inner potentials, they can more easily move towards learning target language autonomously. These independent learners with adequate awareness of their inner potentials in terms of language learning capabilities make the most of every moment of their life to increase their target language knowledge and as its result they are ahead of their other classmates who solely learn within the short length of classroom time period. Furthermore, lesson planners should provide English language books' activities in a way to create characteristics in students that are influential in self-actualization possession. For instance, some sections of book should be dedicated to provoke sense of cooperation in learners and teach them the strategies by which students' negative affective factors are eliminated. In addition, teachers can integrate their instructions with activities by which students' linguistic, intrapersonal, naturalist, existential, and logical-mathematical intelligences are effectively activated. Lastly, teachers should encourage students to confidently develop their abilities and believe that every human is capable of being an expert in various fields if his/her hidden potentials are appropriately realized.

Acknowledgements - We would like to thank all the participants that helped us in collecting data for this study. Our gratitude is also shown to anonymous reviewers for their worthy insights. We are immensely grateful to Consortia Academia Publishing for the publication of this research work.

\section{References}

Armstrong, T. (2009). Multiple intelligences in the classroom (3rd ed.). United States of America: Nancy Modrak.

Arnold, J., \& Fonscca, C. (2004). Multiple intelligence theory and foreign language learning: A brain-based perspective. International Journal of English Studies, 4(1), 119-136.

Bordages, J. W. (1989). Self-actualization and personal autonomy. Psychological Reports, 64, 1263-1266. https://doi.org/10.2466/pr0.1989.64.3c.1263

Derakhshan, A., \& Faribi, M. (2015). Multiple intelligences: Language learning and teaching. International 
ShirzadMoghaddam, E., \& Ghapanchi, Z.

Journal of English Linguistics, 5(4), 63-72. https://doi.org/10.5539/ijel.v5n4p63

Garcia, T., \& Pintrich, P. R. (1991). The effects of autonomy on motivation, use of learning strategies, and performance in the college classroom. Paper presented at the Annual Convention of the American Psychological Association, San Francisco, CA.

Gardner, H. (1999). Intelligence reformed: Multiple intelligences for the 21 st century. New York: Basic Books.

Gardner, H. (2004). A Multiplicity of intelligences. Retrieved from https://llk.media.mit.edu/courses/readings/gardner-multiple-intelligences.pdf

Horwitz, E. K. (2008). Becoming a language teacher: A practical guide to second language learning and teaching. Boston, MA: Pearson.

Jones, A., \& Crandall, R. (1986). Validation of a short index of self-actualization. Personality and Social Psychology Bulletin, 12(1), 63-73. https://doi.org/10.1177/0146167286121007

Khan, M. A., \& Javed, N. R. a. S. (2012). Relationship between faculty's self-actualization and student's faculty evaluation: A case-study. Pakistan Journal of Engineering, Technology \& Science, 2(2), 171-195.

Khodadady, E., \& Khodabakhshzade, H. (2012). The effect of portfolio and self-assessment on writing ability and autonomy. Journal of Language Teaching and Research, 3(3), 518-524. https://doi.org/10.4304/jiltr.3.3.518-524

Khonbi, Z. A., \& Mohammadi, M. (2015). The relationship between Iranian university EFL students' multiple intelligences and their use of language learning strategies: An exploratory study. EuroAmerican Journal of Applied Linguistics and Languages, 2(1), 70-83.

Krejcie, R. V., \& Morgan, D. W. (1970). Determining sample size for research activities. Educational and Psychological Measurement, 30(3), 607-610. https://doi.org/10.1177/001316447003000308

Maslow, A. H. (1943). A theory of human motivation. Psychological Review, 50(4), 370-396. https://doi.org/10.1037/h0054346

Maslow, A. H. (1970). Motivation and personality. New York: Harper \& Row.

McKenzie, W. (2017). Multiple intelligences inventory. Retrieved from http://surfaquarium.com/MI/book1.htm

McLeod, S. (2016). Maslow's hierarchy of needs. Retrieved from https://www.simplypsychology.org/maslow.html

Mehrgan, K. (2012). Humanistic language teaching: A critical look. Advances in Digital Multimedia, 1(4), 184-189.

Mohamadi, M., Alishahi, Z., \& Soleimani, N. (2014). A study on test anxiety and its relationship to test score and self-actualization of academic EFL students in Iran. Procedia - Social and Behavioral Sciences, 98, 1156-1164. https://doi.org/10.1016/j.sbspro.2014.03.529

Najeeb, S. S. R. (2013). Learner autonomy in language learning. Procedia - Social and Behavioral Sciences, 70, 1238-1242. https://doi.org/10.1016/j.sbspro.2013.01.183

Ottó, I. (1998). The relationship between individual differences in learner creativity and language learning success. Tesol Quarterly, 32(4), 763-773. https://doi.org/10.2307/3588011

Pausanos, M. (2014). Emotional intelligence as predictor of self-actualization. University of Bohol Multidisciplinary Research Journal, 2(1), 32-43.

Qamar, M. B. (2016). The impact of learner's autonomy on teaching oral skills (speaking skills) in an EFL classroom. Journal of Language Teaching and Research, 7(2), 293-298. https://doi.org/10.17507/jltr.0702.07

Rawat, A. (2015). A study of the self-sctualization of B.Ed teacher trainees. International Multidisciplinary Research journal, 3(3), 77-82.

Rubio, F. (2007). Self-esteem and foreign language learning. UK: Cambridge Scholars Publishing.

Rosenbloom, M. (2012). Talent vs. potential - Where do you stand? Retrieved from https://www.govloop.com/community/blog/talent-vs-potential-where-do-you-stand/

Sadoski, M., Goetz, E. T., \& Avila, E. (1995). Concreteness effects on text recall: Dual coding or context availability?. Reading Research Quarterly, 30, 278-288. https://doi.org/10.2307/748038

Sahatsatatsana, S., \& Siriyothin, P. (2010). The Improvement of students' English proficiency and intelligences through multiple intelligence integrated syllabus. Paper presented at the 2010 4th International 
On the relationship between multiple intelligences and self-actualization among Iranian EFL learners

Conference on Distance Learning and Educationm (ICDLE), San Juan, Puerto Rico, USA. https://doi.org/10.1109/ICDLE.2010.5606042

Salehi, H., Ebrahimi, M., Sattar, S., \& Shojaee, M. (2015). Relationship between EFL learners' autonomy and speaking strategies they use in conversation classes. Advances in Language and Literary Studies, 6(2), 37-43.

Seidi, A., Dastnaee, T. M., Abadati, N., \& Dehnavi, Z. (2013). Humanizing foreign language instruction based on abraham maslow's hierarchy of needs. ELT Voices - India, 3(6), 40-53.

Ševečková, M. (2016). Creativity in foreign language teaching. Journal of Education Culture and Society, 6(2), 180-188.

ShirzadMoghaddam, E. (2016). From self-reflection to self-actualization towards academic EFL students' success. Academians, 6(3), 19-27.

Tabachnick, B. G., \& Fidell, L. S. (2007). Using multivariate statistics (5th ed.). Boston: Pearson Education.

Weiler, A. (2015). Emotional intelligence and language learning. Retrieved from http://www.strategiesinlanguagelearning.com/emotional-intelligence-and-language-learning/

Zarei, A. A., \& Gahremani, K. (2010). On the relationship between learner autonomy and reading comprehension. Teaching English Language and Literature Society of Iran, 3(10), 81-99. 


\section{Appendix}

Jones and Crandall's (1986) Self-Actualization Index (SAI)

1. I do not feel ashamed of any of my emotions.
A. Disagree
B. Somewhat disagree
C. Somewhat agree
D. Agree

2. I feel I must do what others expect me to do.
A. Disagree
B. Somewhat disagree
C. Somewhat agree
D. Agree

3. I believe that people are essentially good and can be trusted.
A. Disagree
B. Somewhat disagree
C. Somewhat agree
D. Agree

4. I feel free to be angry at those I love.
A. Disagree
B. Somewhat disagree
C. Somewhat agree
D. Agree

5. It is always necessary that others approve of what I do.
A. Disagree
B. Somewhat disagree
C. Somewhat agree
D. Agree
6. I don't accept my own weaknesses.
A. Disagree
B. Somewhat disagree
C. Somewhat agree
D. Agree

7. I can like people without having to approve of them.
A. Disagree
B. Somewhat disagree
C. Somewhat agree
D. Agree

8. I fear failure.
A. Disagree
B. Somewhat disagree
C. Somewhat agree
D. Agree

9. I avoid attempts to analyze and simplify complex domains.
A. Disagree
B. Somewhat disagree
C. Somewhat agree
D. Agree

10. It is better to be yourself than to be popular.
A. Disagree
B. Somewhat disagree
C. Somewhat agree
D. Agree

11. I have no mission in life to which I feel especially dedicated.
A. Disagree
B. Somewhat disagree
C. Somewhat agree
D. Agree

12. I can express my feelings even when they may result in undesirable consequences.
A. Disagree
B. Somewhat disagree
C. Somewhat agree
D. Agree

13. I do not feel responsible to help anybody.
A. Disagree
B. Somewhat disagree
C. Somewhat agree
D. Agree

14. I am bothered by fears of being inadequate.
A. Disagree
B. Somewhat disagree
C. Somewhat agree
D. Agree

15. I am loved because I give love.
A. Disagree
B. Somewhat disagree
C. Somewhat agree
D. Agree 